João Victor Medeiros Barbosa Geografia, Literatura e Arte, v.2, n.1, p. 125-140, jan./jun.2020

\title{
A ROSA DE HIROSHIMA NA VOZ E NO CORPO DE NEY MATOGROSSO
}

\section{HIROSHIMA'S PINK FLOWER IN NEY MATOGROSSO'S VOICE AND BODY}

\section{LA ROSA DE HIROSHIMA EN LA VOZ Y EL CUERPO DE NEY MATOGROSSO}

\author{
João Victor Medeiros Barbosa ${ }^{1}$ \\ CESMAC, Maceió, Brasil
}

Kamilla Maria Medeiros Barbosa ${ }^{2}$

Universidade Federal de Alagoas, Maceió, Brasil

\begin{abstract}
Resumo: $O$ presente trabalho analisa duas realizações de montagens performáticas de Ney Matogrosso distintas entre si da mesma canção, A Rosa de Hiroshima, composta a partir do poema de Vinícius de Moraes. Aborda-se a trajetória artística de Ney Matogrosso a partir da construção de sua autonomia enquanto artista em dois momentos: no grupo Secos e Molhados e após, em sua carreira solo, no show Olhos de Farol, no período de 1973 e 1999, momentos em que realiza sua composição em performance do poema A Rosa de Hiroshima. Observam-se traços peculiares de sua identidade artística em um diálogo entre alguns prismas teóricos sobre a performance e o contexto das suas duas composições, buscando analisar as nuances do movimento do corpo, e sua influência na ressignificação do poema, em cada uma das versões compostas pelo artista.
\end{abstract}

Palavras-chave: Ney Matogrosso; Performance; Rosa de Hiroshima.

Abstract: The present work analyzes two of Ney Matogrosso 's performative montages, from the same song, "A rosa de Hiroshima", composed from the poem by Vinícius de Moraes. The artistic trajectory of Ney Matogrosso is approached from the construction of its autonomy as an artist in two moments: in the group Secos e Molhados and after his solo career, in the show Olhos de Farol, in the period of 1973 and 1999, moments in which he realizes his composition in performance of the poem "The Rose of Hiroshima". Particular traits of his artistic identity are observed in a dialogue between some theoretical prisms about the performance and the context of his two compositions, seeking to analyze the nuances of the movement of the body, and its influence in the resignification of the poem, in each of the composite versions by the artist.

Keywords: Ney Matogrosso; Performance; Rosa de Hiroshima.

Resumen: El presente trabajo analiza dos realizaciones de montajes performáticos de Ney Matogrosso distintas entre sí de la misma canción, "A Rosa de Hiroshima",

${ }^{1}$ CESMAC, Professor de Direito do Trabalho e Direitos Humanos, E-mail: profvictormedeiros@hotmail.com

${ }^{2}$ Universidade Federal de Alagoas, E-mail: kamillakmmb@gmail.com 
João Victor Medeiros Barbosa Geografia, Literatura e Arte, v.2, n.1, p. 125-140, jan./jun.2020

compuesta a partir del poema de Vinícius de Moraes. Se aborda la trayectoria artística de Ney Matogrosso a partir de la construcción de su autonomía como artista en dos momentos: en el grupo Secos \& Molhados y después de su carrera solista, en el show Olhos de Farol, en el período de 1973 y 1999, momentos en que realiza su composición en performance del poema "A Rosa de Hiroshima". Se observan rasgos peculiares de su identidad artística en un diálogo entre algunos prismas teóricos sobre la performance y el contexto de sus dos composiciones, buscando analizar los matices del movimiento del cuerpo, y su influencia en la resignificación del poema, en cada una de las versiones compuestas por el artista.

Palabras clave: Ney Matogrosso; Rendimiento; Rosa de Hiroshima.

Quem deu o direito para alguém determinar caminhos?

Para mim não será.

Vou andar sempre com a minha cabeça aberta e fazer tudo o que tiver vontade.

(Entrevista de Ney Matogrosso - A PRIMEIRA, 2014, s/p.)

\section{INTRODUÇÃO}

O presente artigo traz como objeto a análise de performances do poema $A$ rosa de Hiroshima, de Vinícius de Moraes, realizadas pelo cantor e performer Ney Matogrosso, em dois momentos de sua carreira: enquanto no grupo Secos e Molhados e em sua carreira solo, no show Olhos de Farol. Observa-se também o fazer artístico do performer ligado a essa linguagem, que se mostra através de um corpo que se expressa e se comunica em busca de dar significados à sua arte, a qual também é uma ação social e política e que tem a capacidade de renovação diante das experiências estabelecidas no momento de sua execução e recepção.

O poema em questão foi composto em 1946, quando Vinícius de Moraes exercia a atividade de diplomata; A Rosa de Hiroshima integra a Antologia Poética, 1960, o livro Soneto de fidelidade e outros poemas, 2002, e foi musicado por Gerson Conrad, um dos integrantes do grupo musical Secos \& Molhados. Em 1972, ano de lançamento do primeiro disco da banda, a canção foi uma das mais tocadas no Brasil. A Rosa de Hiroshima apresenta ao mundo o desastre que as bombas atômicas fizeram em Hiroshima e Nagasaki e na história de vida de cada sobrevivente da Segunda Guerra Mundial. A bomba do poema é comparada a uma rosa pela configuração da imagem que se forma ao explodir: a imagem compara-se a uma rosa após desabrochar, mas, obviamente, os efeitos não são os mesmos, não há, nesse acontecimento trágico, a 
João Victor Medeiros Barbosa Geografia, Literatura e Arte, v.2, n.1, p. 125-140, jan./jun.2020 Kamilla Maria Medeiros Barbosa

delicadeza esperada de uma rosa ao abrir-se. Ney Matogrosso, em 1973, momento em que era integrante do grupo Secos e Molhados, através da complexa sinuosidade de seus movimentos e da ondulação de seu corpo, traz ao público a performance de A Rosa de Hiroshima. Anos depois, em 1999, já em sua carreira solo, por meio de um diálogo corporal mais contido, o performer vive uma nova experiência com o poema.

Este artigo tem, portanto, como propósito central analisar a performance de Ney Matogrosso a partir do poema Rosa de Hiroshima, refletindo sobre os movimentos corporais que colaboram para a efetivação da performance. Em um primeiro momento, na parte 1 - Vinícius de Moraes e a Rosa de Hiroshima, será apresentada uma breve biografia de Vinícius de Moraes como poeta e sua relação com o poema Rosa de Hiroshima; em seguida, na parte 2 - A performance e a linguagem corporal, será feita uma passagem pela história da arte performática e, por fim, na parte 3 - As performances de Rosa de Hiroshima, será apresentada a relação artística de Ney Matogrosso com o discurso do corpo e as ressignificações que ele proporcionou ao poema ao inundá-lo de vida e movimento.

\section{PARTE 1: VINÍCIUS DE MORAES E A ROSA DE HIROSHIMA}

\subsection{Vinícius: Vida e obras}

O poeta Vinícius de Moraes, filho de Lydia Cruz de Moraes e de Clodoaldo Pereira da Silva Moraes, nasceu no dia 19 de outubro de 1913, no bairro do Jardim Botânico, Rio de Janeiro, com o nome de batismo Marcus Vinitius da Cruz de Melo Moraes (MORAES, 1987).

Vinícius dedicou sua vida a um modo de viver poético, afirmando as experiências vivenciadas a partir de uma visão artística em diferentes linguagens culturais: na música, no cinema, na literatura, no teatro. Na canção popular brasileira, foi parceiro de compositores considerados gênios da música, como Tom Jobim e Chico Buarque de Hollanda (MORAES, 1987).

Aos 14 anos de idade, através da amizade com os irmãos Paulo, Haroldo e Oswaldo Tapajós, começou a compor suas primeiras canções: Loura ou Morena e Canção da noite (um "fox-trot brasileiro" e uma "berceuse", de acordo com Vinícius). Pouco tempo depois, com os amigos do Colégio Santo Inácio, formou um pequeno 
João Victor Medeiros Barbosa Geografia, Literatura e Arte, v.2, n.1, p. 125-140, jan./jun.2020

grupo musical com a intenção de tocarem em algumas festinhas. Em 1929, Vinícius tornou-se bacharel em Letras pelo mesmo colégio e com apenas 17 anos, em 1930, seguindo o mesmo caminho que muitos jovens traçavam, entrou na Faculdade de Direito da Rua do Catete, no Rio de Janeiro (MORAES, 1987).

Dois anos após, em 1932, publicou pela primeira vez um poema de sua autoria na revista $A$ Ordem, em uma edição de outubro. A publicação, editada pelo intelectual católico e crítico literário Tristão de Athayde, apresentava um jovem e conservador Vinicius, com um poema bíblico de 152 versos intitulado A transfiguração da montanha. Em 1933, com o incentivo do escritor carioca Otávio de Faria conseguiu publicar pela Schmidt Editora seu primeiro livro de poemas: $O$ caminho para a distância (MORAES, 1987).

No ano de 1938, o poeta lançou o livro Novos Poemas, sobre o qual Mario de Andrade fez críticas a Vinícius, afirmando que, diferente de seus livros anteriores, "procurava valer muito mais pela beleza de suas cores que pela ação da própria poesia" (RANGEL, 2007).

Em 1943, publicou seu quinto livro, Cinco elegias, dessa vez com a colaboração luxuosa e decisiva de alguns amigos, dentre eles Manuel Bandeira - que se tornou um grande horizonte para Vinicius no final da década de 30 -: "Naturalmente, estas cinco elegias vão escandalizar muita gente (a ausência de poesia em certas pessoas dá pena). Vai haver choro e ranger de dentes" (BANDEIRA, 2004, p.87). Segundo Candido, (1992, apud RANGEL, 2007, p.13) são:

(...) poemas densos, escritos entre 1937 e 1939, nos quais a pesquisa metafísica dos primeiros tempos foi canalizada para representar a naturalidade do amor, a inquietação relacionada à experiência corrente, o mistério traduzido em familiaridade e temperado com uma espécie de humor sem agressão - traços que nunca mais sairiam de suas receitas. É notável o sentido experimental da linguagem, que o levou inclusive a jogar com aspectos visuais, tão em moda atualmente.

Três anos depois lançou Poemas, sonetos e baladas. Em 1954, lançou sua Antologia Poética, que contou com a colaboração de Manuel Bandeira mais uma vez. Três anos depois lançou Livro de Sonetos. Nesse intervalo, Vinícius escreveu dezessete novos poemas, reafirmando sua dicção lírica e lançando temas inéditos em sua poesia, que estavam reunidos no livro Novos Poemas II (MORAES, 1987). 
João Victor Medeiros Barbosa Geografia, Literatura e Arte, v.2, n.1, p. 125-140, jan./jun.2020

O poeta lançou seu livro $A$ arca de Noé, que foi a reunião de poemas criados para seus filhos Susana e Pedro, e que ficaram guardados por muito tempo até ganharem alcance do público. O livro tornou-se um de seus mais populares pela relação criada com o universo infantil e os laços criados com as crianças (MORAES, 1987).

Em 1978 foram lançados os livros $O$ falso mendigo e Amor total. Em 9 de julho de 1980, por causa de um edema pulmonar, ao lado de Toquinho e sua esposa Gilda Mattoso, Vinícius morre em sua casa na Gávea (MORAES, 1987).

Sua poética modernista expõe, entre outros aspectos diversos, o que há no profundo das aflições humanas, o eterno impasse entre a aceitação do "real" inconstante e a recorrente fantasia do inesgotável. Amor, mas também a reflexão sobre o ser, a angústia das aflições existenciais, o mutável e o imutável, o empenho crítico social e o fazer poético são alguns dos temas sobre os quais Vinícius de Moraes constrói sua extensa história literária (MORAES, 1987).

\subsection{A Rosa de Vinícius}

Os poetas que valem realmente fazem a poesia dizer mais coisas do que ela dizia antes deles.

(CANDIDO, 2004, s/p.)

Rosa de Hiroshima, poema de Vinícius de Moraes, foi escrito em 1946 e publicado em 1954, no livro Antologia Poética. A partir de uma postura humanista, marcado pelo propósito ideológico de denúncia e pela impotência do ser humano enquanto sociedade, frente a um mundo frio e cruel que é reduzido a um objeto "sem cor, sem perfume, sem rosa, sem nada", o poeta opõe-se à Segunda Guerra Mundial através desse poema, recriando, metaforicamente, todo o cenário de destruição e falta de perspectivas que existiram para as pessoas envolvidas no massacre em Hiroshima, em 1945 (ANTOLOGIA, 2009).

O poema torna perpétua a lembrança do que não deveria ser esquecido. Em Rosa de Hiroshima, a bomba atômica nos faz refletir sobre um paradoxo inteligente e intenso entre a destruição e a fragilidade, entre o terror e a beleza: 
João Victor Medeiros Barbosa Geografia, Literatura e Arte, v.2, n.1, p. 125-140, jan./jun.2020 Kamilla Maria Medeiros Barbosa DOI: 10.11606/issn.2594-9632.geoliterart.2020.157134

Pensem nas crianças

Mudas telepáticas

Pensem nas meninas

Cegas inexatas

Pensem nas mulheres

Rotas alteradas

Pensem nas feridas

Como rosas cálidas

Mas oh não se esqueçam

Da rosa da rosa

Da rosa de Hiroshima

A rosa hereditária

A rosa radioativa

Estúpida e inválida

A rosa com cirrose

A antirrosa atômica

Sem cor sem perfume

Sem rosa sem nada.

(ANTOLOGIA, 2009, p.253)

A esse cenário, o poeta acrescenta a imagem de uma antirrosa atômica, que é bela e trágica, e não convida a aguçar características simples de uma rosa, mas convida à morte.

Refletindo um pouco sobre a estrutura do poema de Vinícius, pode-se pensar que ele se inicia pelo fim da guerra e finaliza com sua causa, que é a própria bomba. O poeta faz uso também de estratégias para conseguir levar o leitor a fazer determinadas interpretações, artimanhas que estão presentes nas figuras de linguagem que são empregadas no decorrer do texto: através da metáfora, expõe a relação da bomba atômica com uma rosa ao desabrochar, incluindo semelhanças e diferenças entre os dois objetos; da antítese, quando relaciona os caminhos que o sexo feminino traça até chegar à fase adulta (crianças, meninas, mulheres), como se representasse seres que gozariam do desenvolvimento da vida, mas que tiveram esse processo natural sendo quebrado pelas cinzas que o atentado deixou ("rotas alteradas") (ANTOLOGIA, 2009, p. 253); e, 
João Victor Medeiros Barbosa Geografia, Literatura e Arte, v.2, n.1, p. 125-140, jan./jun.2020

por fim, por meio da comparação, "feridas como rosas cálidas", ao expressar as feridas que marcavam a pele, o psicológico e o sentimento de mundo.

Sobre essa modalidade poética de Vinícius, em que as palavras não assumem papeis autônomos e isolados, Antonio Candido afirma que o poeta "fez poesia com palavras concatenadas de maneira a obter uma sequência semântica que dissolve a autonomia delas num discurso poético articulado. (...) ele é um poeta de continuidades, não de rupturas" (CANDIDO, 2008, p. 159).

Ao usar o verbo 'pensar' no modo imperativo ("pensem") no decorrer do texto, o poeta propõe a reflexão sobre as atrocidades causadas pela guerra no geral, mas, principalmente, sobre as ações desumanas que o ser humano pratica ao esquecer o quanto de humanidade há dentro de si, através, nesse caso, da bomba atômica. No meio do poema, encontra-se o verso: "Mas, oh, não se esqueçam", também no modo imperativo, é um chamado à reflexão de que a culpa e responsabilidade da destruição é de toda a humanidade, do que o ser humano pode oferecer ao seu semelhante. Assim, é possível dizer o poema não trata somente da catástrofe em Hiroshima, mas também da própria existência, a própria sobrevivência humana.

Rosa de Hiroshima, ao trazer à tona essa triste cena da Segunda Guerra Mundial, denunciando o fato ocorrido em Hiroshima, parece se contrapor a qualquer intenção de guerra, pois qualquer bomba atômica utilizada contra algo/alguém provocaria as mesmas dores, os mesmos gritos e os mesmos silêncios.

O poema de Vinícius de Moraes, ao ser incorporado por Ney Matogrosso, em duas experiências distintas entre si de cantar e dançar os versos, imprime em Rosa de Hiroshima uma instância performática, na medida em que, ao justapor diferentes linguagens (musical, corporal, cênica), reitera o texto em movimentos vivenciados no corpo.

\section{PARTE 2: A PERFORMANCE E A LINGUAGEM CORPORAL}

Esse espaço da experiência corpórea possibilita ao artista constituir uma representação de si, que, por conseguinte, lhe disponibiliza dramatizar sua existência com determinado contexto. (SILVA, 2013, s/p.) 
João Victor Medeiros Barbosa Geografia, Literatura e Arte, v.2, n.1, p. 125-140, jan./jun.2020

Quando inserida no universo da canção, a arte performática é peça fundamental: ela permite que a relação entre o artista e o público seja permeável entre si, e a maneira como o discurso do corpo acontece influencia na recepção do outro:

A relação arte-corpo é, por essência, uma relação de fundamental importância sobre vários pontos de vista. Em primeiro lugar, porque o trabalho do corpo nas performances institui um contato direto entre emissor e receptor sem a intermediação técnica de nenhum equipamento eletrônico moderno exceto pela utilização de som ou vídeo. Por esse motivo, aquela relação mencionada é de enfrentamento, e elimina os significados que cada meio de comunicação agrega por sua conta aos conteúdos que transmite. (GLUSBERG, 2011, p. 59)

A performance explora o corpo como reflexão da própria arte performática, desfetichizando o corpo humano, retirando dele a exaltação à beleza a que ele foi elevado por muitos anos, possibilitando ao artista representar-se, dramatizar seu existir no mundo ao interagir com um determinado contexto.

A partir desse pressuposto, levou-se a valorizar a corporeidade, com ênfase no gestual e oral. Sendo o corpo como a própria conexão da arte com a vida e estudo das diversas áreas do conhecimento artístico e cientifico, tendo ele como objeto e palco da própria existência humana. (SILVA, 2013, p.1)

Outro fator determinante na performance é considerar que ela é a soma de muitas linguagens. Ela é capaz de transgredir códigos vigentes através de efeitos comportamentais, o que a partir da relação com o público, permite que ele comece a aceitar, entender a nova linguagem artística a que está exposto e a criar expectativas relacionadas àquela linguagem corporal.

Assim, a performance vai ter em comum com outros exemplos da arte contemporânea a necessidade de ser interpretada e julgada à luz de um enriquecimento cultural do receptor, sem o qual o transgressivo se converte simplesmente em algo aborrecedor ou também num total nonsense. (GLUSBERG, 2011, p. 64)

Ney Matogrosso, ao trazer para cena, explorando tanto aspectos da iluminação quanto sonoros e gestuais, numa dança inusitada, parece instaurar uma dimensão performática à sua incorporação do poema Rosa de Hiroshima, assumindo inclusive 
João Victor Medeiros Barbosa Geografia, Literatura e Arte, v.2, n.1, p. 125-140, jan./jun.2020 Kamilla Maria Medeiros Barbosa

DOI: 10.11606/issn.2594-9632.geoliterart.2020.157134

distintos caminhos cênicos para a sua recepção do poema. Nesse sentido, a performance do cantor performático parece carregar consigo uma relação intensa entre o que se canta e o cantor. A partir desse encontro, o artista traz à tona e reconfigura significados implícitos e explícitos na letra da música que interferem na maneira como a plateia entende a letra e o diálogo do corpo com ela, suscitando outras sensações.

\section{PARTE 3: AS PERFORMANCES DE ROSA DE HIROSHIMA}

\section{1 -Ney Matogrosso e o diálogo de seu corpo}

Com o nome de batismo Ney de Souza Pereira, Ney Matogrosso nasceu em primeiro de agosto de 1941, na cidade de Bela Vista - MS. Após se mudar para São Paulo, adotou o nome artístico que o consagrou no país: Matogrosso fazia parte do sobrenome de seu pai. Aos cinco anos de idade, quando sua mãe o levou para assistir a um programa na Rádio Nacional, ele presenciou a apresentação da atriz, cantora e compositora Elvira Pagã; desde então, seu espírito foi tocado pelo encanto da arte. De espírito livre desde pequeno, o artista costumava se meter na mata próxima a sua casa quando voltada da escola e de lá só saía ao anoitecer. Assim, ele sentia que fazia parte da natureza. Por volta dos nove, dez anos, Ney Matogrosso descobriu a magia e o prazer de desenhar, assim, decidiu que queria estudar pintura. No entanto, conhecera o significado de repressão desde cedo, seu pai, militar, impedia-o de seguir o desejo que mantinha, pois não desejava que o filho seguisse carreira artística alguma (MATOGROSSO, 2016).

Por manter uma relação muito conflituosa com os pais, principalmente com o pai, aos dezessete anos resolveu se alistar no serviço militar para poder, então, sair de casa. Seguiu para o Rio de Janeiro. Prestou serviço nos anos de 1959 e 1960. Sua vivência em diversos lugares do país lhe trouxe experiências diferentes: o candomblé da Bahia, a natureza do Mato Grosso, o jeito carioca do Rio de Janeiro, o teatro de São Paulo e a liberdade de Brasília, que era uma cidade nova, vazia. Em Brasília, fez parte de um coral de música erudita e começou a cantar vários clássicos, mas considerava sua voz estranha para o canto, opinião que não era compartilhada por sua professora de canto. Assim, foi convidado a participar de um festival universitário promovido pela Universidade de Brasília. Contra o gosto da professora, que achava sua voz adequada 
João Victor Medeiros Barbosa Geografia, Literatura e Arte, v.2, n.1, p. 125-140, jan./jun.2020

para os clássicos, Ney Matogrosso se apresentou cantando MPB. Após várias apresentações em festivais, boates e programas de TV alternativos, o artista revolveu voltar ao Rio de Janeiro (MATOGROSSO, 2016).

Durante esse período, recebeu um convite da cantora e compositora Luli para passar um tempo em sua residência ensaiando algumas canções despretensiosamente. Aconteceu, então, da compositora apresentar Ney Matogrosso a João Ricardo que estava prestes a formar um grupo musical, o conhecido Secos \& Molhados (MATOGROSSO, 2016).

O surgimento do grupo se deu num momento da história marcado por dois grandes processos que geraram mudanças culturais no país: a vigência do regime ditatorial militar, com a intensificação da censura; e o segundo, de natureza técnica, com o novo arranjo das indústrias da cultura, havendo uma superação da fase marcada por certa artesanalidade (MATOGROSSO, 2016).

O artista levou para o interior do grupo sua autonomia artística, seu princípio de criação e tudo o que o teatro tinha oferecido. Para ele, a primeira personagem existe a partir de um tipo de máscara.

[...] mesmo tendo a pintura surgido sem querer, mesmo em um universo aparentemente de puro acaso, as personagens são importantes porque contam as histórias da música e são uma constante inovação na performance. (SILVA, 2013, p. 44)

$\mathrm{O}$ rosto todo pintado protege o homem e cria a personagem. A histeria que os Secos \& Molhados provocava assustava o artista e a máscara funcionava como uma proteção do assédio do mundo.

[...] Fiz aquela máscara na época do Secos \& Molhados para me proteger. Foi intencionalmente. Eu ouvia dizer que artistas não tinham vida particular. Como assim? Eu não ia poder mais andar na rua? Então, fiz aquela máscara para proteger a minha identidade. Funcionou por muito tempo. Eu ia à praia e ficava ouvindo comentários sobre aquele homem que se requebrava todo no palco. E eu ao lado das pessoas, só escutando (risos) (MATOGROSSO, 2016, s/p.).

No começo, a mídia se referia ao grupo como 'um grupo de homossexuais', o que escandalizava o público da época. Contudo, a estética do conjunto atraiu e permitiu 
João Victor Medeiros Barbosa Geografia, Literatura e Arte, v.2, n.1, p. 125-140, jan./jun.2020

uma diversidade de público, o que colaborou para driblar a censura, evitando, assim, que o grupo fosse vetado.

Quando eu tô no palco eu não tenho essa coisa de homem ou mulher, eu sou um ser, um artista no palco se exibindo para o público. Fora do palco eu quero passar desapercebido, eu prefiro observar que ser observado. (MATOGROSSO, 2010, s/p.).

Ney Matogrosso explorou semioticamente o espaço que lhe foi dado, soltou corpo e a voz e realizou performances repletas de movimentos sensuais, caretas, com o corpo semi nu e sempre ameaçando ir mais além. "Seu projeto era, claramente, diluir aquelas fronteiras estanques entre o masculino e o feminino nos mais mínimos gestos." (NOGUEIRA, 2016, p.778). Quanto mais a censura agia, mais agressiva e sexual era sua performance. Quanto mais se sentia reprimido, mais solto e ousado ficava.

As apresentações performáticas do Secos \& Molhados em canais televisivos garantia grande audiência e grande aceitação por parte de um público amplo e diversificado. Mas, após alguns problemas internos do grupo, em agosto de 1974, Ney partiu para a carreira solo. Em março de 1975, ele estreou seu show Homem de Neanderthal, no Rio de Janeiro, que contou com uma ousada superprodução com belos cenários, iluminação impecável e ele surgindo no palco meio bicho/meio homem, coberto por peles, chifres e penas, figurinos de exclusiva criação. Sete meses depois do fim de Secos e Molhados, Ney Matogrosso lançou seu primeiro disco solo, "Água do Céu-Pássaro", e foi duramente julgado pela crítica brasileira.

Ainda assim, Ney Matogrosso conseguiu se tornar um artista relativamente autônomo, levando em consideração a limitação de liberdade que havia no Brasil naquela época e as regras da indústria fonográfica brasileira.

\subsection{A Rosa de Ney}

\subsection{1 - Secos e Molhados}

O Secos \& Molhados não era precisamente um grupo musical formado nos padrões cimentados da música pop a partir da década de 60 , em que as bandas abrigavam certo equilíbrio entre os cantores e os instrumentistas, evitando que um 
João Victor Medeiros Barbosa Geografia, Literatura e Arte, v.2, n.1, p. 125-140, jan./jun.2020

estivesse acima do outro em papeis e reconhecimento no grupo (ZAN, 2013). Através da performance de Ney, o "gestus", termo utilizado por Zumthor (2000), revelava sua força na combinação da sonoridade dos instrumentos e dos arranjos com o poema cantado, de maneira que as inflexões vocais eram parte inerente à atitude corporal. "O gestus dá conta de que uma atitude corporal encontra seu equivalente numa inflexão de voz, e vice-versa, continuamente" (ZUMTHOR, 2000, p.244).

Os movimentos de resistência pélvicos, os rebolados marcantes, as expressões faciais agressivas não parecem criar uma espécie de tensão com a leveza que transparece em sua voz ao cantar. Os adereços combinados com as características físicas e a expressão corporal transgressora, fluída e mutável de Ney tornam clara a sensação de que "a performance não nos apresenta estereótipos preconcebidos e sim criações espontâneas e verdadeiras" (GLUSBERG, 2011, p.59). Em sua apresentação, música, gestualidade, cenário e indumentária conversam entre si, fazendo da performance uma reinvenção da estética.

Observando a apresentação de Ney Matogrosso no vídeo 1 (SECOS, 2012), é possível observar que sua movimentação parte do movimento dos membros superiores combinado com o centro do corpo, usando os braços e o tórax, inclinado para a frente para iniciar a performance. Nessa sua interpretação, há uma espécie de agressividade, combinada com fluidez, e expansão - através dos movimentos de braços abertos parece remeter à imagem da bomba de Hiroshima explodindo nas cidades: como se os membros superiores estivessem invadindo/tomando conta do espaço ao redor. Esse tipo de movimento é o que Klauss Vianna reconhece como resistência - através de seu corpo,

criando, assim, uma força de resistência, resultando num movimento mais denso e mais amplificado, que dá a característica do corpo cênico, com tônus muscular elevado, diferenciado do tônus cotidiano. [...] Com a presença da resistência, o corpo ganha tridimensão (as dimensões: frente/atrás, cima/baixo, lados direito/esquerdo). Expandindo as costas em relação à frente, percebemos todas as direções do corpo, suas laterais, o ápice da cabeça projeta-se pra cima, enquanto os pés enraizados fazem oposição, empurrando e ativando, dessa forma, o corpo inteiro. [...] Possibilitando, assim, mais clareza e limpeza de movimento, além da prontidão e da força de sustentação do corpo como um todo (MILLER, 2007, p.70-71). 
João Victor Medeiros Barbosa Geografia, Literatura e Arte, v.2, n.1, p. 125-140, jan./jun.2020

A resistência é combinada também com um movimento de leveza, por meio da delicadeza de sua voz e do tempo desacelerado no qual o corpo discursa com a palavra cantada, paradoxo que o poema de Vinícius de Moraes reflete bem ao relacionar a violência da bomba de Hiroshima com uma flor, símbolo da fragilidade. A ondulação de seu movimento e a sensação de liberdade e fluidez que acontecem por causa da qualidade de suas expressões corporais são marcas registradas de Ney Matogrosso.

\section{Ney Solo}

Em março de 1975, sete meses após seu desligamento com o grupo Secos \& Molhados, Ney Matogrosso inicia carreira solo. Nesse novo período, traçou um lento processo para tornar-se um artista autônomo frente às imposições mercadológicas que buscavam controlar sua liberdade artística. Em sua performance, foi menos pulsante a necessidade do artista em usar maquiagens muito marcantes ou gestos mais agressivos, mas, ainda assim, continuou a transgredir as condutas sociais, com a predominância de padrões machistas, por meio de sua atuação cênica andrógina. Nesse cenário político e social, construiu sua autonomia.

O primeiro sentido a ser observado na performance acontecida em seu show Olhos de Farol - 1999, no vídeo 2 (NEY, 2011) é a mudança de visual do artista, diferente do que se via no Secos \& Molhados, em que havia o gosto em se apresentar com fantasias, criando personagens marcantes, usando a nudez e a sensualidade. A mensagem, a partir de então, tornou-se mais direta. A interpretação de Rosa de Hiroshima, em sua fase de carreira solo, segue o compasso de súplica ou de um estado de alerta.

Ney Matogrosso inicia a sua performance com os braços cruzados diante de seu rosto, numa espécie de movimento de negação. Seu movimento é mais contido, o que Ciane Fernandes, por meio do sistema Laban/Bartenieff, expressa como fluxo contido ou controlado "controlado e controlável/ cada movimento/ é restrito/ e cuidadoso" (FERNANDES, 2006, p.107). Assim, os gestos performáticos são a representação da fragilidade dos momentos, da vida diante do terror que a bomba de Hiroshima provocou. O movimento dos membros superiores cobrindo o rosto e o peito representa proteção de um corpo externo que fere, de uma realidade enfrentada sozinho, os 
João Victor Medeiros Barbosa Geografia, Literatura e Arte, v.2, n.1, p. 125-140, jan./jun.2020 Kamilla Maria Medeiros Barbosa

movimentos são lentos - algo que está relacionado "com o "quando" do movimento, a intuição e a decisão ao realizá-lo" (FERNANDES, 2006, p.117)-, o olhar permanece distante como se em cada lugar em que o olho encontra morada existisse uma espécie de vazio diferente ou simplesmente estivesse procurando em si mesmo esse vazio. Apenas em um momento de sua performance, no trecho "pensem nas mulheres, rotas alteradas", Ney Matogrosso altera seu movimento e impulsiona o corpo para a frente, posicionando-se como alguém que enfrenta o vazio deixado pela explosão, colocandose na posição de quem sofreu o terror. Mas, logo em seguida, em "a rosa radioativa, estúpida e inválida", há novamente uma expressão de medo, como se ao falar as características da rosa, ele se aproximasse de uma imagem que não há como não temer.

\section{CONSIDERAÇÕES FINAIS}

Este artigo buscou analisar duas composições de Ney Matogrosso, a partir do poema Rosa de Hiroshima de Vinicius de Moraes, relacionando-as a conceitos da arte performática, destacando prismas teóricos de Jorge Glusberg (2011) e Zumthor (2000, 2005) buscando o entendimento das nuances das performances de Ney Matogrosso, através da análise das gravações de apresentações do artista.

As gravações visuais de espetáculos são constituídas em si mesmas uma interpretação e não uma representação da manifestação viva - já que as imagens gravadas são alteradas por cortes e ângulos, o que deixa, de certa forma, algumas lacunas na performance em relação à sua expressividade, singular ao tempo e espaço social em que foi produzida - a performance torna-se irreparável em sua integridade, assim como em sua completude. Contudo, a importância da análise e a escolha dos dois momentos do artista surgem pela relevância em explorar o quanto a passagem de tempo, a realidade social da época - o grupo Secos \& Molhados surgiu num contexto de ditadura, enquanto em carreira solo, sua trajetória já passava por outra realidade política e midiática - e o amadurecimento de Ney enquanto artista influenciaram em sua atuação performática e em sua autonomia diante de sua arte.

Comparando os dois momentos, percebemos que há um Ney Matogrosso diferente em cada uma das fases analisadas. Enquanto integrante do S\&M, mantinha em suas apresentações uma performance mais sensual, provocativa - um excesso de gestos e 
João Victor Medeiros Barbosa Geografia, Literatura e Arte, v.2, n.1, p. 125-140, jan./jun.2020

elementos, dando foco principalmente no uso dos quadris e braços. Em sua apresentação no show Olhos de Farol, o artista se expõe através de um personagem mais contido nos adereços e na maquiagem, assim como no discurso entre seu corpo e o poema cantado.

Ney Matogrosso preservou durante sua carreira o desejo de manter-se autônomo. Ao montar cada apresentação, Ney cria um novo personagem, que acontece em função de seu princípio de autonomia e criação, buscando despertar em seus espectadores suas identidades e o desejo de romper com tabus e conceitos. Uma perspectiva que o mantinha "fora" da tentativa de disciplinarização do corpo, que era imposta principalmente pela censura durante o regime militar, gerando, assim, uma ruptura estética e comportamental. O artista alcançou, portanto, o que é próprio do instituinte: manter-se 'fora' de algo que classifica.

\section{REFERÊNCIAS}

"A PRIMEIRA vez que o meu pai me viu actuar tomou um remédio para o coração". Reportagem publicada em 02 mai.2014 no jornal iSapo on line. Disponível em: <https://ionline.sapo.pt/263734>. Acesso em: 1 jan. 2018.

BANDEIRA, Manuel. "Coisa Alóvena, Ebaente". In Vinicius de Moraes: poesia completa e prosa. Org. Eucanaã Ferraz. Rio de Janeiro: Nova Aguilar, 2004, pp. 87-89.

CANDIDO, Antonio. "Um poema de Vinicius de Moraes". In: Teoria e debate, n. 49. São Paulo: Fundação Perseu Abramo, out-dez. 2001, pp. 70-71. Poemas, sonetos e baladas e Pátria minha. São Paulo: Companhia das Letras, 2008. p. 159-162.

CANDIDO, Antonio. [Vinicius de Moraes]. In: FERRAZ, Eucanaã (org.). Vinicius de Moraes: poesia completa e prosa. Rio de Janeiro: Nova Aguilar, 2004. p. 120-122.

FERNANDES, Ciane. O corpo em movimento: o sistema Laban/Bartenieff na formação e pesquisa em artes cênicas. São Paulo: Annablume Editora, 2006.

GLUSBERG, Jorge.1932- . A arte da performance.[tradução Renato Cohen]. São Paulo: Perspectiva, 2011.

MATOGROSSO, Ney. Trajetória. 2016. Disponível em: <http://www2.uol.com.br/neymatogrosso/depoim07.html>. Acesso em: 27 jul. 2016.

MATOGROSSO, NEY. Beijo bandido. DVD. Canal Brasil e EMI, 2010.

NEY Matogrosso - Rosa de Hiroshima - 25 set.2011. (2m40s). Disponível em: https://www.youtube.com/watch?v=sR1gC4GsFGM. . Acesso em 10 mai.2019. 
João Victor Medeiros Barbosa Geografia, Literatura e Arte, v.2, n.1, p. 125-140, jan./jun.2020

MILLER, Jussara. A escuta do corpo: sistematização da Técnica Klauss Vianna. São Paulo: Summus, 2007.

MORAES, Vinícius de. Antologia Poética. 1a ed. São Paulo: Companhia das Letras, 2009.

MORAES, Vinícius de. Vida e obra. 1987. Disponível em: <http://www.viniciusdemoraes.com.br/pt-br/vida.> Acesso em: 25 set. 2016.

NOGUEIRA, Fernanda. Metamorfose ambulante. A desidentificação carnavalesca de Ney Matogrosso na militadura brasileira. ETD - Educação Temática Digital, Campinas, SP, v. 18, n. 4, p. 769-788, nov. 2016. ISSN 1676-2592. Disponível em: <doi:http://dx.doi.org/10.20396/etd.v18i4.8646425>.Acesso em: 16 nov. 2016.

RANGEL, Valéria. $O$ amor entre o vão momento e o infinito: os sonetos de Vinícius de Moraes. 2007. Dissertação (Mestrado em Teoria Literária e Literatura Comparada). Faculdade de Filosofia, Ciências e Letras Humanas - Universidade de São Paulo, 2007.

SECOS e Molhados - Rosa de Hiroshima - 03 out.2012. (2m03s). Disponível em: https://www.youtube.com/watch?v=DwVc0G3IKU4. Acesso em 10 mai.2019.

SILVA, Vitória Angela Serdeira Honorato Silva. A performance de Ney Matogrosso: inovação na canção midiática em dois momentos. São Caetano do Sul: USCS.Campus II, 2013.

ZAN, José Roberto. "Secos e Molhados: metáfora, ambivalência e performance". ArtCultura, Uberlândia, v. 15, n. 27, p. 7-27, jul.-dez., 2013.

ZUMTHOR, Paul. Escritura e nomadismo: entrevistas e ensaios-Cotia, SP: Ateliê Editorial, 2005.

ZUMTHOR, Paul. Performance, Recepção, Leitura. São Paulo: Educ, 2000.

Recebido em 18/04/2020.

Aceito em 04/09/2020.

Publicado em 15/10/2020. 